\title{
Quantitative Analysis of Flavor and Other Volatiles and for Certain Constituents of Two Tomato Cultivars during Ripening
}

\author{
E.A. Baldwin, M.O. Nisperos-Carriedo, and M.G. Moshonas \\ U.S. Department of Agriculture, Agricultural Research Service, Citrus and Subtropical Products \\ Laboratory, Winter Haven, FL 33883-1909
}

\begin{abstract}
Additional index words. Lycopersicon esculentum, ethylene, carbon dioxide, climacteric, organic acid, glucose, fructose, sucrose, sampling technique

Abstract. Tomato (Lycopersicon esculentum Mill.) fruit, cvs. Sunny and Solar Set, were analyzed at five ripening stages for ethylene and $\mathrm{CO}_{2}$ production. Homogenates from the same fruit were prepared for determination of color, flavor volatiles, sugars, and organic acids. Changes in the levels of these compounds were compared to the pattern of climacteric ethylene production. Of the flavor volatiles measured, only eugenol decreased during ripening in both cultivars and 1-penten-3-one in 'Sunny' tomatoes. Ethanol and trans-2-trans- 4-decadienal levels showed no change or fluctuated as the fruit ripened while all other volatiles measured (cis- 3-hexenol, acetaldehyde, cis- 3-hexenal, trans-2hexenal, hexenal acetone, 6-methyl-5 -hepten-2-one, geranylacetone, and 2-isobutylthiazole) increased in concentration, peaking in the turning, pink, or red stage of maturity. Synthesis of some volatile compounds occurred simultaneously with that of climacteric ethylene, $\mathrm{CO}_{2}$ and lycopene production. 'Solar Set' fruit exhibited higher levels than 'Sunny' of all flavor components except ethanol and hexanal in the red stage. There were no differences in organic acid levels between the cultivars; however, 'Solar Set' had higher levels of sugars. Changes in acid and sugar levels showed no temporal relationship to climacteric ethylene or $\mathrm{CO}_{2}$ production.
\end{abstract}

Sensory characteristics, such as flavor and texture, are important to fruit and vegetable production, since the ultimate quality is determined largely by these characteristics. Culture of the plant, time of harvest, postharvest treatments, and genetic control (cultivar) may influence these quality attributes (Dirinck et al., 1989). Objective analysis of these sensory traits would also be of interest to breeders to select better tasting fruits and vegetables, such as the tomato.

Considerable research has been directed toward measuring tomato flavor but largely from the standpoint of sugar : acid ratios (Jones and Scott, 1984; Kader et al., 1978; Stevens et al., 1977). Little attention has been focused on the contribution of volatiles to tomato flavor. Although $\approx 400$ volatiles have been identified, only the following have been singled out as having important roles in fresh tomato flavor; hexanal, trans- 2-hexenal, cis- 3-hexenal, cis- 3-hexenol, trans-2-trans- 4-decadienal, 2-isobutylthiazole, 6-methyl-5-hepten-2-one, 1-penten-3-one, and ( $\beta$ ionone (Buttery et al., 1971, 1987, 1988; Ho and Ichimura, 1982; Petro-Turza, 1987). Others are abundant but of unknown or disputed importance to flavor. Extraction and analysis of these volatiles is tedious and time consuming. Consequently, few quantitative data are available on flavor volatiles in tomatoes, their behavior during ripening, and their fate during postharvest handling and storage.

The purpose of this research was to conduct a quantitative study of volatile synthesis during tomato ripening in relation to other, more-studied ripening events in two tomato cultivars. The volatiles studied are either abundant or of reported importance to tomato flavor. The procedure for aroma analysis consisted of a new headspace sampling technique that allows direct sampling

Received for publication 25 June 1990. Trade names are used for information purposes. Mention of trade names does not constitute a guarantee or warranty of the products by the U.S. Dept. of Agriculture, nor does it imply endorsement over similar commercial products. Appreciation is extended to Philip Shaw for use of equipment, Aldys Foerster for technical support, and Jay Scott for fruit. The cost of publishing this paper was defrayed in part by the payment of page charges. Under postal regulations, this paper therefore must be hereby marked advertisement solely to indicate this fact. of tomato homogenates, thus eliminating the need to extract volatiles before analysis.

\section{Materials and Methods}

Fruit. We used 'Sunny', which is grown commercially, and 'Solar Set', a recent release of the Univ. of Florida Gulf Coast Research Station. Mature-green fruit were harvested at the station, washed, and allowed to ripen in storage chambers at $21 \mathrm{C}$. Five fruits from each cultivar were removed for analysis at five stages of ripening: mature green (no red evident but locule gel formation initiated), breaker ( $<10 \%$ red), turning (30\% to $60 \%$ red), pink ( $70 \%$ to $90 \%$ red) and red (>90\% red).

Analysis of $\mathrm{CO}_{2}$, ethylene, and color. Carbon dioxide and ethylene were measured by sealing the fruit for $1 \mathrm{hr}$ in glass jars with lids fitted with rubber septa. Gas samples $(1 \mathrm{ml})$ were removed from the headspace by syringe and analyzed on a Perkin Elmer 8500 gas chromatography (Perkin Elmer, Norwalk, Corm.) equipped with activated alumina, Poropac S, Poropac $\mathrm{Q}$ (Supelco, Bellefonte, Pa.) and molecular sieve columns connected to flame ionization and thermal conductivity detectors. Gas levels were identified and quantified by comparison of retention times and peak areas with those of standards. Whole fruit (five fruit per cultivar from each ripening stage) were then individually homogenized at room temperature for $30 \mathrm{sec}$ using a Waring blender. Homogenate color was analyzed for $a$ and $b$ values using a scale of red and green ( $a$ and $b$, respectively) on a Minolta CR-200 Chroma Meter (Minolta, Ramsey, N.J.) adjusted with a white standard tile. Data for redness (a) and hue angle $\left(\tan ^{-1} \mathrm{a} / \mathrm{b}\right)$ are presented (Cheng and Shewfelt, 1988; Goodenough and Thomas, 1981).

Analysis for sugars and acids. Fruit homogenate (40 g) was added to $70 \mathrm{ml}$ of $80 \%$ ethanol, boiled for $15 \mathrm{~min}$ (with a loosefitting cover), cooled, and vacuum-filtered through Whatman \#4 filter paper. The resulting extract was brought up to $100 \mathrm{ml}$ with $80 \%$ ethanol; and $20 \mathrm{ml}$ then was passed through a C-18 Sep Pak (Waters/Millipore, Milford, Mass.) and a $0.45-\mu \mathrm{m}$ Millipore filter. The filtered extract was injected by a Bio-Rad AS-100 HPLC autosampler (Bio-Rad, Richmond, Calif.), fitted 
with a $20-\mu$ l sample loop, into a Perkin Elmer Series 410 HPLC system. Sugars were analyzed using a Waters Sugar Pak column at 90C with a mobile phase of $100 \mu \mathrm{M}$ ethylenediamine-tetraacetic acid disodium-calcium salt (CaEDTA) and a flow rate of $2 \mathrm{ml} \cdot \mathrm{min}^{-1}$. Acids were separated on an Interaction Ion-300 column (Mountain View, Calif. ) at $65 \mathrm{C}$ with a mobile phase of $0.0008 \mathrm{~N}$ sulfuric acid at a flow rate of $0.4 \mathrm{ml} \cdot \mathrm{min}^{-1}$. A Perkin Elmer LC-25 Refractive Index detector and Perkin Elmer LC85B Spectrophotometric detector at $210 \mathrm{~nm}$ were used to measure sugars and acids, respectively. Filtered analytical grade reagents were used for standard preparation to establish high performance liquid chromatography (HPLC) retention times and calibration. Determination of purity of individual peaks was accomplished by absorbance index (all wavelengths monitored simultaneously) on a Perkin Elmer LC-235 Diode Array detector.

Analysis of volatile flavor components. Tomato volatiles were quantified using a method developed for citrus fruit and juice products (Nisperos-Carriedo and Shaw, 1990), modified for tomato. Homogenate $(2 \mathrm{ml})$ from five-fruit samples per ripening stage and cultivar were transferred to 6-ml vials with crimp-top caps and seals and immediately stored at - 20C. Preliminary studies had shown that volatile levels remained constant for up to 3 months of frozen storage. Volatile flavor components were determined using a Perkin Elmer model 8500 gas chromatography equipped with a Model HS-6 headspace sampler, a 0.53 $\mathrm{mm} \times 30 \mathrm{~m}$ polar Durowax column (1.0- $\mu \mathrm{m}$ film thickness; J\&W Scientific, Folsom, Calif.) and a flame ionization detector. Helium head pressure was $42 \mathrm{kPa}\left(81 \mathrm{~cm} \cdot \mathrm{s}^{-1}\right.$ linear gas velocity). Tomato samples were 'equilibrated in the headspace sampler for $15 \mathrm{~min}$ at $80 \mathrm{C}$ before injection. The headspace sampler used a $0.5-\mathrm{min}$ vial pressurization time followed by $0.02-\mathrm{min}$ injection. The column oven was at $40 \mathrm{C}$ for $6 \mathrm{~min}$ and programmed to raise the temperature at $6 \mathrm{C} / \mathrm{min}$ to $180 \mathrm{C}$, where it was held for $10 \mathrm{~min}$. The FID amplifier range setting was for high sensitivity and the detector temperature was 250C. The components were identified by comparison of retention times with those of standards and by enrichment of tomato homogenates with authentic samples. Concentrations were calculated using regression equations, determined by injecting five concentrations of each standard to obtain a peak height calibration curve. The standard dilutions were prepared by addition of $4 \mu \mathrm{l}$ of an aqueous ethanolic solution of standards to $2 \mathrm{ml}$ of bland tomato homogenate from which most volatile components had been removed by distillation at 60C.

Mass spectra. Presence of the volatile components noted above in tomato homogenate was confirmed by gas chromatographymass spectrometry (GC-MS). Tomato homogenate was centrifuged $(11,000 \times \mathrm{g}$ for $15 \mathrm{~min})$ and the supernatant extracted with ethyl ether. The organic fraction was examined for volatile compounds. A Hewlett-Packard Model 5970B, MSD, GC-MS was used with a $50-\mathrm{m}$-wide bore $(0.31$ to $0.32 \mathrm{~mm})$ fused silica column of cross-linked 590 phenylmethyl silicone. Column oven temperature programming was $55 \mathrm{C}$ for $9 \mathrm{~min}$, then raised at $7.5 \mathrm{C} / \mathrm{min}$ to $220 \mathrm{C}$ and held there for $30 \mathrm{~min}$. Injector port and ionizing source were kept at $275 \mathrm{C}$, and transfer line at $280 \mathrm{C}$. Mass units were monitored from 25 to 350 at $70 \mathrm{eV}$. Mass spectral matches were made by comparison of mass spectra and retention times with those of authentic compounds.

Statistics. The experiment involved a factorial arrangement of treatments (two cultivars $\times$ five maturity stages) in a completely randomized design. Data were tested by analysis of variance using the General Linear Model (GLM) procedure of the
Statistical Analysis System (SAS Institute, Cary, N.C.). Specific differences between treatments were determined by Tukey's Studentized Range (HSD). Mean differences between treatment combinations were determined by least square means. All comparisons were done at $P=0.05$. (SAS/STAT Guide, 1987).

\section{Results}

Ethylene, $\mathrm{CO}_{2}$, and color analysis. Results for ethylene, $\mathrm{CO}_{2}$, and color (Fig. 1) are typical for what has been reported previously for ripening tomato fruit (Brady et al., 1987). Ethylene production increased significantly at the breaker and turning stages and leveled off at the pink and red stages. Ethylene production by 'Sunny' was significantly higher than that of 'Solar Set' at the breaker stage, although the difference between cultivars for total ethylene levels was not significant. $\mathrm{CO}_{2}$ levels for 'Solar Set' increased steadily throughout ripening while those for 'Sunny' were significantly lower and dropped off in the later stages of ripening.

There were significant and progressive decreases in hue angle starting at the turning stage of ripening, by which time ethylene production had reached relatively high levels (Fig. 2A). The hue angle reflects both a decrease in greeness (chlorophyll) and a simultaneous increase in redness (lycopene and other carotenoids). When ' $a$ ' values (red) are examined alone, however, a significant increase occurred by the breaker stage with only a low ('Solar Set') to moderate ('Sunny') increase in ethylene production (Fig. 2B).

Sugar and acid analysis. Total sugar levels showed a general increase followed by no change or a slight decrease during ripening (Fig. 3). This trend is in agreement with trends in other studies (Davies and Kempton, 1975; Goodenough et al., 1982). The changes in sugar levels were significant only for glucose, however. The breaker and turning stages exhibited significantly higher levels of this sugar than the other ripening stages for the combined data from the two cultivars (the mature-green fruit samples for 'Solar Set' sugar analysis were lost). Sucrose levels decreased to undetectable levels in both cultivars during ripening. 'Solar Set' tomatoes had significantly higher levels of both glucose and fructose than 'Sunny' (the green stage was excluded for this analysis).

There were no significant differences between the two cultivars for organic acid content, with the exception of higher levels

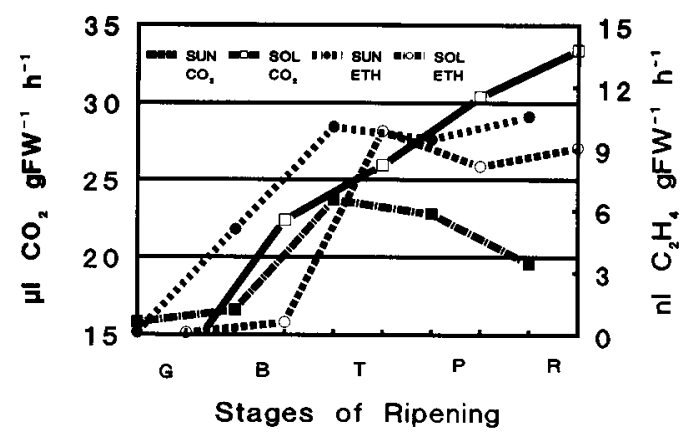

Fig. 1. $\mathrm{CO}_{2}$ and ethylene production in 'Sunny' (SUN) and 'Solar Set' (SOL) tomatoes at the mature-green $(G)$, breaker (B), turning $(\mathrm{T})$, pink $(\mathrm{P})$ and red $(\mathrm{R})$ ripening stages. Values are means of five replications. The ANOVA table had nine degrees of freedom. Ethylene: $\mathrm{F}$ value $=13.58$, ripening $\operatorname{Pr}>0.0001(\mathrm{HSD}=3.58)$, cultivar $\operatorname{Pr}>0.6932(\mathrm{HSD}=1.59) ; \mathrm{CO}_{2}: \mathrm{F}$ value $=12.25$, ripening $\operatorname{Pr}>0.0001(\mathrm{HSD}=5.36)$, cultivar $\operatorname{Pr}>0.0001(\mathrm{HSD}=2.38)$. 
A

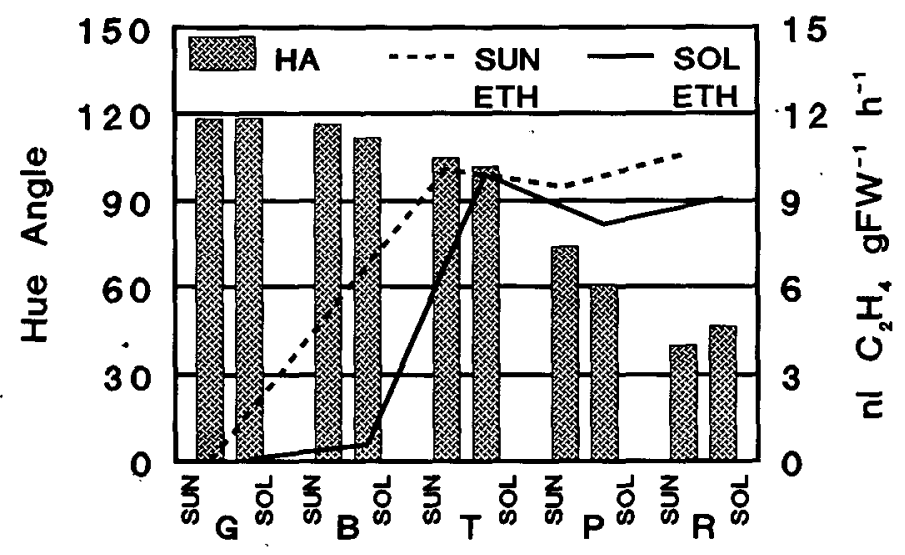

B

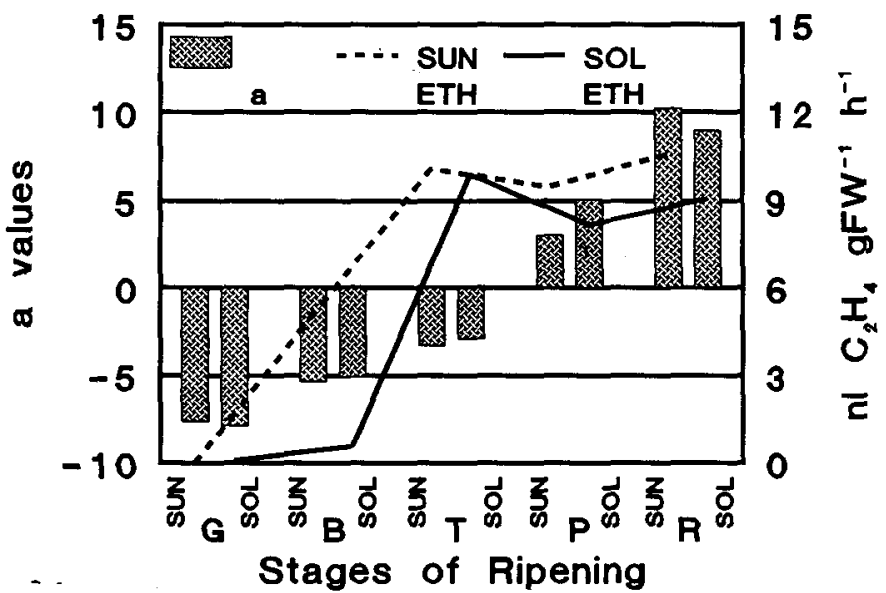

Fig. 2. Color development and ethylene production in 'Sunny' (SUN ETH) and 'Solar Set' (SOL ETH) tomatoes at the mature-green (G), breaker $(B)$, turning $(T)$, pink $(P)$, and red $(R)$ ripening stages. $(A)$ bars represent hue angle (HA), (B) 'a'values. Values are means of five replications. The ANOVA table for color had nine degrees of freedom. Hue angle: $F$ value $=209.07$, ripening $\operatorname{Pr}>0.0001$ (HSD $=6.25)$, cultivar $\operatorname{Pr}>0.0413(\mathrm{HSD}=2.78)$; ' $\mathrm{a}$ ' values: $\mathrm{F}$ value $=137.02$, ripening $\operatorname{Pr}>0.0001$ (HSD $=1.69$ ), cultivar $\operatorname{Pr}>$ $0.5269(\mathrm{HSD}=0.75)$.

of fumaric acid in 'Sunny' tomatoes in the later stages of ripening (Fig. 4 A and B). Malic and fumaric acid concentrations decreased significantly during the later stages of ripening while citric, oxalic, and succinic generally increased (Fig. $4 \mathrm{~A}$ and B). There was no relationship between ethylene production and changes in sugar and acid levels.

Flavor volatile analysis. The flavor components were grouped into alcohols (Fig. $5 \mathrm{~A}$ and B); aldehydes (Fig. 6); and ketones and one sulfur-containing volatile (Fig. 7). Of the two cultivars, 'Solar Set' had significantly higher levels overall of the following components: eugenol and cis- 3-hexenol (Fig. 5 A and B); acetaldehyde and cis- 3-hexenal (Fig. 6); and acetone and 6methyl-5-hepten-2-one (Fig. 7). Red 'Solar Set' tomatoes had significantly higher levels of the above mentioned components as well as of trans- 2-hexenal (Fig. 6) and 2-isobutylthiazole (Fig. 7). Changes in individual flavor volatiles during ripening

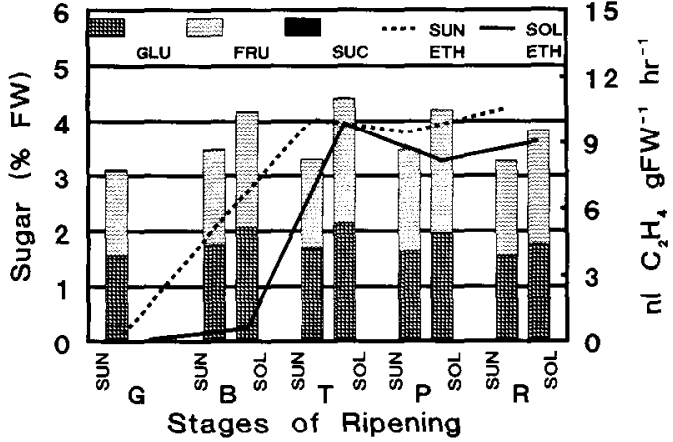

Fig. 3. Glucose (GLU), fructose (FRU), and sucrose (SUC) concentration and ethylene production in 'Sunny' (SUN ETH) and 'Solar Set' (SOL ETH) tomatoes at the mature-green (G), breaker (B), turning $(T)$, Pink $(P)$ and red $(R)$ ripening stages. Values are means of five replications. The ANOVA table had nine degrees of freedom. Glucose: $F$ value $=6.86$, ripening $\operatorname{Pr}>0.0291(\mathrm{HSD}=0.28$, cultivar $\operatorname{Pr}>0.0001$ ( $\mathrm{HSD}=0.12$ ); fructose: $\mathrm{F}$ value $=7.45$, ripening $\operatorname{Pr}>0.5999(\mathrm{HSD}=0.29)$, cultivar $\mathrm{Pr}>0.0001$ (HSD $=$ 0.13 ); sucrose: $\mathrm{F}$ value $=7.31$, ripening $\operatorname{Pr}>0.0001$ (HSD $=$ $0.019)$, cultivar $\operatorname{Pr}>0.5477$ ( $\mathrm{HSD}=0.008$ ). Total Sugars: $\mathrm{F}$ value $=4.08$, ripening $\operatorname{Pr}>0.9658(\mathrm{HSD}=0.686)$, cultivar $\operatorname{Pr}>0.0001$ $(\mathrm{HSD}=0.305)$.

were also analyzed. Eugenol was the only volatile component that decreased significantly during ripening (Fig. 5A). During ripening of both cultivars, significant increases were observed for the following: cis- 3-hexenol (Fig. 5B); all aldehydes except trans-2-trans- 4-decadienal, which fluctuated (Fig. 6); and all ketone compounds except for 1-penten-3-one, which decreased in 'Sunny' fruit (Fig. 7). Geranylacetone appeared only in the red stage in 'Sunny' fruit. The sulfur-containing volatile measured, 2-isobutylthiazole, increased significantly during ripening in both cultivars (Fig. 7).

Comparison of our quantitative results for red tomato with data reported by other workers using different techniques of analysis show some differences. Levels for hexenal and trans2-hexenal were high in our fruit (9.0 and $2.5 \mathrm{ppm})$ compared to reported values of 3.5 and $0.33 \mathrm{ppm}$, respectively (Buttery et al., 1987, 1988). Conversely, cis- 3-hexenal was low (2.5 ppm) compared to a reported value of 10.0 ppm (Buttery et al., 1987, 1988). Some cis-trans isomerization may have occurred during sample preparation.

\section{Discussion}

Volatile compounds that characterize fresh tomato flavor are reported to be derived from fatty- and amino-acid metabolism and breakdown of carotenoids (Buttery et al., 1971, 1988; Heath and Reiniccius, 1986; Petro-Turzo, 1987). The homogenization of tomato fruit facilitates contact between enzymes and their substrates and introduces excess air. This situation may enhance the formation of enzymic oxidation products (Buttery et al., 1971). Although care was taken to process the samples quickly (within $5 \mathrm{~min}$ ), some volatile compounds may have increased or decreased due to this procedure.

Our study shows that the concentration of individual volatiles increased during ripening (peaking in the pink or red stage of development). The trend of synthesis of some volatiles followed the increased production of ethylene and lycopene and the climacteric rise in respiration during ripening. There is a possibility that some volatiles may be regulated by this hormone either directly or indirectly via lycopene. The volatiles 6-methyl- 


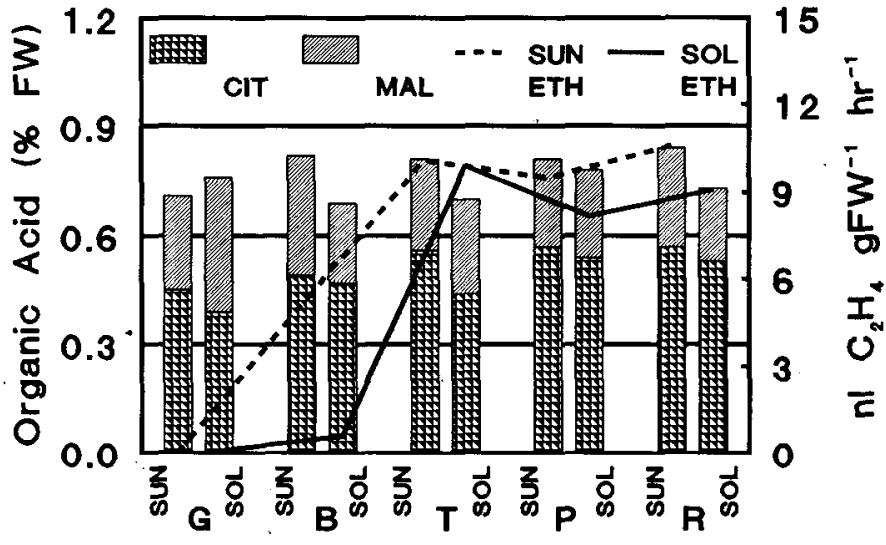

B

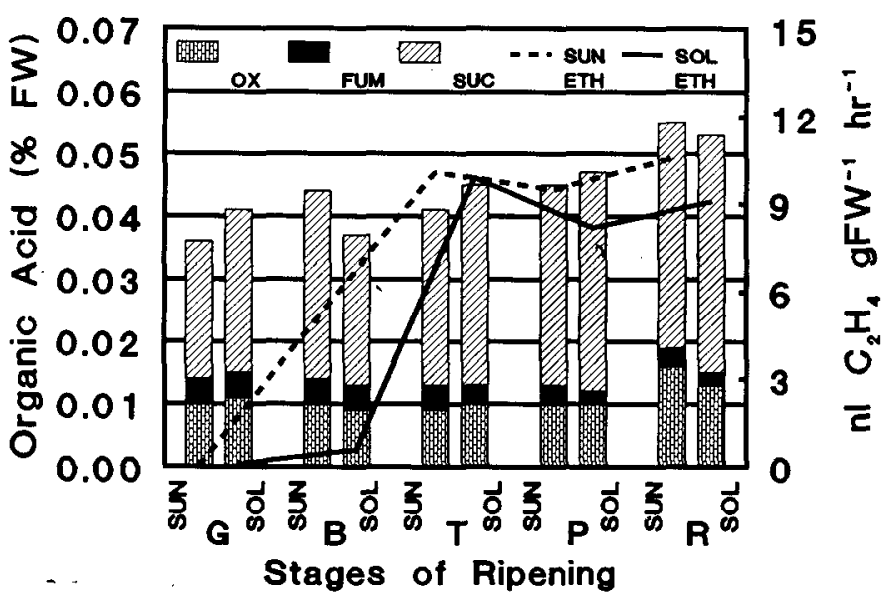

Fig. 4. Organic acid concentration and ethylene production in 'Sunny' (SUN ETH) and 'Solar Set' (SOL ETH) tomatoes at the maturegreen $(\mathrm{G})$, breaker $(\mathrm{B})$, turning $(\mathrm{T})$, pink $(\mathrm{P})$ and red $(\mathrm{R})$ ripening stages. (A) Citric (CIT) and malic (MAL) acid levels. (B) oxalic (OX), fumaric (FUM) and succinic (SUC) acid concentrations. Values are means of five replications. The ANOVA table had nine degrees of freedom. Citric acid: $F$ value $=2.53$, ripening $\mathrm{Pr}>$ 0.0075 ( $\mathrm{HSD}=0.114$ ), cultivar Pr $>0.4967(\mathrm{HSD}=0.051)$; malic acid: $F$ values $=3.97$, ripening $\operatorname{Pr}>0.0323(\mathrm{HSD}=0.076)$, cultivar $\operatorname{Pr}>0.5853$ (HSD $=0.034$ ); oxalic acid: $F$ value $=2.67$, ripening $\operatorname{Pr}>0.002(\mathrm{HSD}=0.004)$, cultivar $\operatorname{Pr}>0.8416(\mathrm{HSD}=$ 0.002 ); fumaric acid: $F$ value $=2.65$, ripening $\operatorname{Pr}>0.0387$ (HSD $=0.0015$ ), cultivar $\operatorname{Pr}>0.0071$ ( $\mathrm{HSD}=0.0007$ ); succinic acid; $\mathrm{F}$ value $=2.09$, ripening $\operatorname{Pr}>0.0089$ (HSD $=0.0108$ ), cultivar $\operatorname{Pr}>0.5610($ HSD $=0.0048)$.

5-hepten-2-one and geranylacetone are suspected lycopene breakdown-products (Buttery et al., 1988). A relatively small rise in ethylene in the breaker stage occurred simultaneously with a significant color change as seen in 'Solar Set' fruit (Fig. $2 \mathrm{~B})$. This rise is also associated with the appearance or substantial increase in the levels of some important flavor volatiles: cis- 3-hexenol (Fig. 5B), cis- 3-hexenal, trans- 2-hexenal (Fig. 6), 6-methyl-5-hepten-2-one, and 2-isobutylthiazole (Fig. 7). The bland flavor of the nonripening mutants rin and nor, which produce little or trace levels of ethylene and lycopene, is attributed to the absence of certain intense aroma compounds found

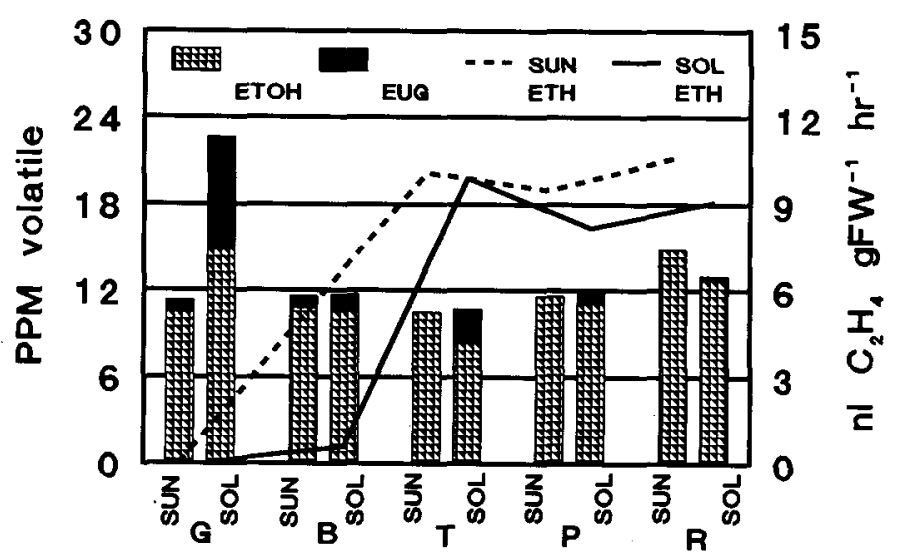

B

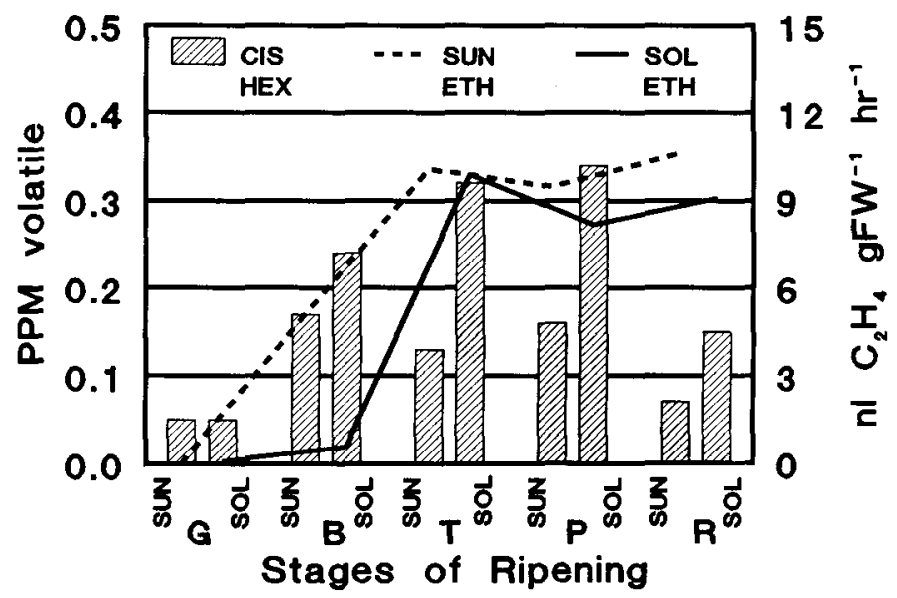

Fig. 5. Alcohol volatiles and ethylene production in 'Sunny' (SUN ETH) and 'Solar Set' (SOL ETH) tomatoes at the mature-green (G), breaker (B), turning (T), pink (P), and red (R) ripening stages. (A) ethanol (ETOH) and eugenol (EUG) levels; (B) cis-3-hexenol (CIS HEX). Values are means of five replications. The ANOVA table had nine degrees of freedom. ETOH: $\mathrm{F}$ value $=1.10$, ripening $\mathrm{Pr}$ $>0.188$ (HSD $=5.52$ ), cultivar $\operatorname{Pr}>0.9906$ ( $\mathrm{HSU}=2.46$ ); EUG: $F$ value $=3.59$, ripening $\operatorname{Pr}>0.0081$ (HSD $=3.365)$, cultivar $\operatorname{Pr}$ $>0.0083$ (HSD $=1.50) ; \mathrm{CIS}$ HEX: $\mathrm{F}$ value $=2.71$, ripening $\mathrm{Pr}$ $>0.0094(\mathrm{HSD}=0.189)$, cultivar $\operatorname{Pr}>0.0313(\mathrm{HSD}=0.084)$.

in a normal ripening tomato, such as 'Rutgers' (McGlasson et al., 1987). The evidence for regulation of volatiles by ethylene is circumstantial, however. Sugars, acids, and volatiles may also have been influenced by changes in respiration as fruit metabolism converted to catabolism during the climacteric and post-climacteric period of ripening. The subject of regulation requires further research before any conclusions can be made.

Tomato flavor is partially due to the presence of sugars and acids. Previous studies have shown that malic, oxalic, and fumaric acids decreased and citric acid increased, fluctuated, or decreased during ripening (Davies, 1962; Goodenough et al., 1982; Sakiuama and Stevens, 1976; Thorne and Efiuvwevwere, 1988). The data presented here show similar results except for an increase in oxalic and succinic acids observed during ripening. A previous report indicated that changes in sugar and 


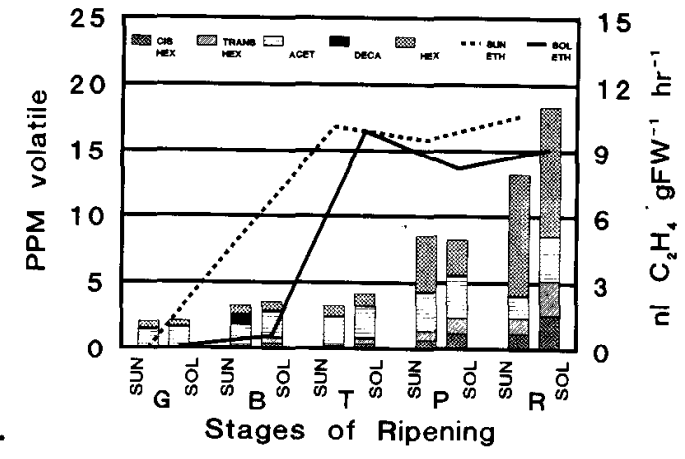

Fig. 6. Aldehyde volatiles, cis-3-hexenal (CIS HEX), trans-2-hexenal (TRANS HEX), acetaldehyde (ACET), trans-2-trans-4-decadienal (DECA), hexanal (HEX), and ethylene production in 'Sunny' (SUN ETH) and 'Solar Set' (SOL ETH) tomatoes at the maturegreen $(G)$, breaker $(B)$, turning $(T)$, pink $(P)$, and red $(R)$ ripening stages. Values are means of five replications. The ANOVA table had nine degrees of freedom. CIS HEX: $F$ value $=23.18$, ripening $\operatorname{Pr}>0.001$ (HSD -0.498 ), cultivar $\operatorname{Pr}>0.0001$ ( $\mathrm{HSD}=0.222$ ); TRANS HEX: $\mathrm{F}$ value $=16.42$, ripening $\operatorname{Pr}>0.0001(\mathrm{HSD}=$ 1.184), cultivar $\operatorname{Pr}>0.2195$ (HSD $=0.528$ ); ACET (aldehyde): $F$ value $=4.16$, ripening $\operatorname{Pr}>0.001$ (HSD $=0.998$ ), cultivar $\operatorname{Pr}>$ $0.0132(\mathrm{HSD}=0.445) ; \mathrm{DECA}: \mathrm{F}$ value $=2.37$, ripening $\mathrm{Pr}>$ 0.0022 (HSD $=0.074)$, cultivar $\mathrm{Pr}>0.6499(\mathrm{HSD}=0.033) ; \mathrm{HEX}$ : $\mathrm{F}$ value $=12.35$, ripening $\mathrm{Pr}>0.001(\mathrm{HSD}=3.056)$, cultivar $\mathrm{Pr}$ $>0.8132(\mathrm{HSD}=1.36)$.

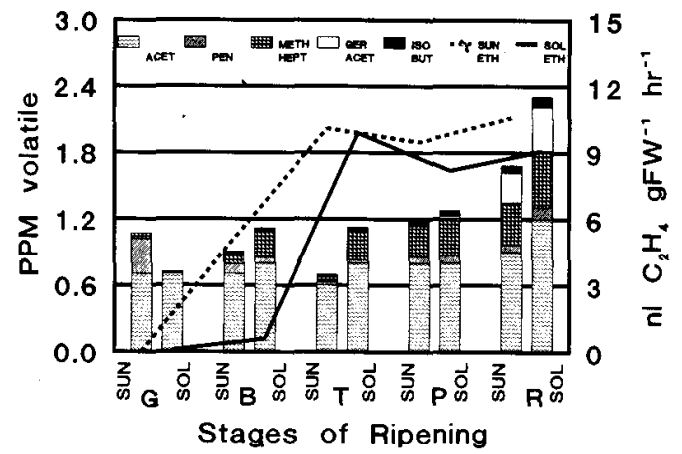

Fig. 7. Ketone volatiles, acetone (ACET), 1-penten-3-one (PEN), 6methyl-5-heptenone (METH HEP), geranylacetone (GER ACET), and 2-isobutylthiazole (ISO BUT), a sulfur-containing compound, and ethylene production in 'Sunny' (SUN ETH) and 'Solar Set' (SOL ETH) tomatoes at the mature-green $(\mathrm{G})$, breaker (B), turning $(\mathrm{T})$, pink $(\mathrm{P})$, and red $(\mathrm{R})$ ripening stages. Values are means of five replications. The ANOVA table had nine degrees of freedom. ACET(one): $F$ value $=2.98$, ripening $\operatorname{Pr}>0.0001(\mathrm{HSD}=0.278)$, cultivar $\operatorname{Pr}>0.0197$ ( $\mathrm{HSD}=0.125)$; $\mathrm{PEN}$ : $\mathrm{F}$ value $=1.75$, ripening $\operatorname{Pr}>0.0293$ ( $\mathrm{HSD}=0.067$ ), cultivar $\mathrm{Pr}>0.9840$ ( $\mathrm{HSD}=$ 0.03 ); METH HEP: F value $=24.32$, ripening $\operatorname{Pr}>0.0001$ (HSD $=0.092$ ), cultivar $\operatorname{Pr}>0.0046(\mathrm{HSD}=0.041)$; GER ACET: $\mathrm{F}$ value $=2.37$, ripening $\operatorname{Pr}>0.0022(\mathrm{HSD}=0.270)$, cultivar $\operatorname{Pr}>$ $0.6499(\mathrm{HSD}=0.012)$; ISO BUT: $\mathrm{F}$ value $=7.40$, ripening $\mathrm{Pr}>$ $0.0001(\mathrm{HSD}=0.03)$, cultivar $\operatorname{Pr}>0.0636(\mathrm{HSD}=0.013)$.

acid levels occurred independently of ethylene and other ripening changes (Jeffery et al., 1984). Similarly, no relationship between climacteric ethylene and changes in sugar and acid levels was evident in this study.

The levels of sugars and acids may differ among cultivars (Kader et al., 1978; Stevens et al., 1977). Tomato volatiles, which also contribute to fresh tomato flavor (Buttery et al., 1971), showed differences among the two cultivars analyzed in this study. Quantitative comparison of desirable flavor volatiles in addition to reducing sugars and free acids in tomato breeding lines would be a useful tool in selecting for a better tasting tomato, determining effect of harvest date, and optimizing postharvest storage conditions and duration. From the objective measurements presented here, it would appear that 'Solarset' tomatoes were sweeter and had more flavor than 'Sunny' fruit. Such a conclusion, however, would need to be verified by a larger sample size along with sensory evaluation.

\section{Literature Cited}

Brady, C., B. McGlasson, and J. Speirs. 1987. The biochemistry of fruit ripening, p. 279-288. In: D. Evans and R. Jones (eds.). Tomato biotechnology. Alan R. Liss Inc., New York.

Buttery, R.G., R.M. Seifert, D.G. Guadagni, and L.C. Ling. 1971. Characterization of additional volatile components of tomato. J. Agr. Food Chem. 19(3):524-529.

Buttery, R.G., R. Teranishi, and L.C. Ling. 1987. Fresh tomato aroma volatiles: a quantitative study. J. Agr. Food Chem. 35:540-544.

Buttery, R.G., R. Teranishi, L.C. Ling, R.A. Flath, and D.J. Stern. 1988. Quantitative studies on origins of fresh tomato aroma volatiles. J. Agr. Food Chem. 36:1247-1250.

Cheng, T.S. and R.L. Shewfelt. 1988. Effect of chilling exposure of tomatoes during subsequent ripening. J. Food Sci. 53(4):1160-1162.

Davies, J.N. 1962. The non-volatile organic acid of tomato fruit. Proc. 1st Intl. Congr. Food Sci. Technol. 1:509-516.

Davies, J.N. and R.J. Kempton. 1975. Changes in the individual sugars of tomato fruit during ripening. J. Sci. Food Agr. 26:1103-1110.

Dirinck, P., H. De Pooter, and N. Schamp. 1989. Aroma development in ripening fruits, p. 23-34. In: R. Teranishi, R.G. Buttery, and F. Shahidi (eds.). Flavor chemistry: Trends and developments; ACS Symp. Ser. 388. Amer. Chem. Soc., Washington, D.C.

Goodenough, P.W. and T.H. Thomas. 1981. Biochemical changes in tomatoes stored in modified gas atmospheres. 1. Sugars and acids. Assn. Applied Biol. 98(3):507-515.

Goodenough, P.W., G.A. Tucker, S. Grierson, and T. Thomas. 1982. Changes in colour, polygalacturonase monosaccharides and organic acids during storage of tomatoes. Photochemistry 21(2):281-284.

Heath, H.B. and G. Reineccius. 1986. Flavor chemistry and technology. Van Nostrand Reinhold, New York.

Ho, C. and N. Ichimura. 1982. Identification of heterocyclic compounds in the volatile flavour of fresh tomato. Lebensmittel-Wissenschaft und Technol. 15(6):340-342.

Jeffery, D., C. Smith, P. Goodenough, I. Prosser, and D. Grierson. 1984. Ethylene-independent and ethylene-dependent biochemical changes in ripening tomatoes. Plant Physiol. 74:32-38.

Jones, R.A. and S.J. Scott. 1984. Genetic potential to improve tomato flavor in commercial $F_{1}$ hybrids. J. Amer. Soc. Hort. Sci. 109(3):318-321.

Kader, A.A., L.C. Morris, M.A. Stevens, and M. Albright-Holton. 1978. Composition and flavor quality of fresh market tomatoes as influenced by some postharvest handling procedures. J. Amer. Soc. Hort. Sci. 103:6-13.

McGlasson, W.B., J.H. Last, K.J. Shaw, and S.K. Meldrum. 1987. Influence of the non-ripening mutants rin and nor or the aroma of tomato fruit. HortScience z2(4):632-634.

Nisperos-Carriedo, M.O. and P.E. Shaw. 1990. Comparison of volatile flavor components in fresh and processed orange juices. J. Food Agr. Chem. 38:10481052.

Paz, O., H.W. Janes, B.A. Prevost, and C. Frenkel. 1981. Enhancement of fruit sensory quality by post-harvest applications of acetaldehyde and ethanol. J. Food Sci. 47:270-276.

Petro-Turza, M. 1987. Flavor of tomato and tomato products. Food Rev. Intl. 2(3):309-351.

Sakiyama, R. and M.A. Stevens. 1976. Organic acid accumulation in attached and detached tomato fruits. J. Amer. Soc. Hort. Sci. 10(4):394-396.

Saltveit, M.E. 1989. Effect of alcohols and their interaction with ethylene on the ripening of epidermal pericarp discs of tomato fruit. Plant Physiol. 90:167174.

SAS/STAT Guide for Personal Computers. Version 6. 1987. R.C. Luginbuhl and S.D. Schlotzhauer, eds. SAS institute, Cary, N.C.

Stevens, M.A., A.A. Kader, M.A. Albright-Holton, M. Algazi. 1977. Genotype variation for flavor and composition in fresh market tomatoes. J. Amer. Soc. Hort. Sci. 102(9):680-689.

Thorne, S.N. and B.J.O. Efiuvwevwere. 1989. Changes in organic acids in chilled tomato fruit (Lycopersicon esculentum Mill). J. Sci. Food Agr. 44:309319 . 